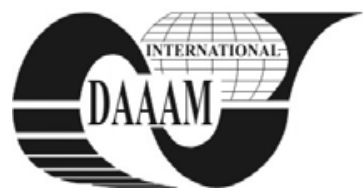

Annals of DAAAM for 2011 \& Proceedings of the 22nd International DAAAM Symposium, Volume 22, No. 1, ISSN 1726-9679 ISBN 978-3-901509-83-4, Editor B. Katalinic, Published by DAAAM International, Vienna, Austria, EU, 2011 Make Harmony between Technology and Nature, and Your Mind will Fly Free as a Bird Annals \& Proceedings of DAAAM International 2011

\title{
ANALYSIS OF THE INFLUENCE OF SOME EXTERNAL VARIABLES ON EMPLOYEES' JOB SATISFACTION
}

\author{
PUIA, R[amona] S[tefania]; ZDOROVETCHI, C[ristina] A[lexandrina] \& AGOSTON, S[imona]
}

\begin{abstract}
Most of the studies regarding job satisfaction aim the analysis of the influence which some internal factors - related to the organisation and its management - have on the "level of happiness" of the employees, as job satisfaction has been named. However, we cannot exclude the influence some factors outside the organization, macroeconomics, which may modify the employees' spirit and therefore their satisfaction regarding their work. In this paperwork, we analyzed the way a series of external variables influence the employees' job satisfaction, variables which are also used in other surveys that analyze the relationship between job satisfaction and work quality (Van Saane and others (2003), Hardré (2009), Muñoz de Bustillo Llorente \& Fernández Macías, (2005)).
\end{abstract}

Key words: human resource management, human resources, job satisfaction, external variables

\section{INTRODUCTION}

Job satisfaction was, over time, a subject intensely studied in a very large number of national and international studies by specialists in organizational management as well as physiologists or sociologists. At international level, there wasn't reached an agreement regarding the best method of measuring job satisfaction. (European Foundation for the Improvement of Living and Working Conditions, 2007). The most used methods in order to evaluate job satisfaction are the interview and the questionnaire. No matter what method is used, generally there are two approaches regarding the evaluation of job satisfaction: a holistic approach that measures the global satisfaction of the employees through general questions, as “Are you satisfied with your work?”; a factorial approach of the evaluation that measures the facet satisfaction bringing into attention the fact that job satisfaction is influenced by different aspects of the job, named facets, two persons being able to have the same level of global satisfaction but influenced by totally different reasons. On the other hand, there are many surveys that analyze the way a series of macroeconomic indicators may influence the employees' satisfaction from a country. In this paperwork I analyzed the way a series of external variables influence the employees' job satisfaction, variables also used in other studies, which analyze the relationship between job satisfaction and the quality of work (Van Saane and others (2003), Hardré (2009), Muñoz de Bustillo Llorente \& Fernández Macías, (2005)). However, as I noticed, although the data are from different years, the results of the surveys are very similar. The variables were:

- GDP/capita (in PPP)

- Unemployment rate

- Overwork (percent of the active population that work more that 50 hours per week),

- Index of the real income

The correlations that exist between these variables have been tested though a comparative analysis of the level of the satisfaction from different countries and the quantum of the proposed indicators.
The data regarding the level of job satisfaction in different countries were taken over from the international database International Social Survey Programme (ISSP 2005), dates that are used in the surveys of other specialists (Muñoz de Bustillo Llorente \& Fernández Macías, (2005)). This database is the result of an yearly developed programme, since 1983, coordinated by the University of Cologne. The programme benefits of a transnational collaboration and covers more important themes for the research in the social science field. The information regarding the level of job satisfaction refers to a number of 32 countries/regions that are part of the last questionnaire developed regarding work orientation: Work Orientation III (ISSP 2005). We mention the fact that Romania is no part of this survey, so far not being involved in a significant survey, at national level, regarding job satisfaction.

As far as the macroeconomic variables taken into account are concerned, we used the data provided by The Key Indicator of the Labour Market (KILM 2005) - a multi-functional research instrument developed by the International Labour Office and International Labour Organization. KILM represents one of the top indicators at international level being used on daily basis by thousands of researchers.

\section{MAIN RESULTS OF THE ANALYSIS}

The analysis of the satisfaction level recorded in the $\mathbf{3 2}$ countries stresses a surprising fact: between the analyzed countries there are very small differences regarding the level of job satisfaction. However, the obtained result is according to anterior analysis effectuated on the same indicators"(Muñoz de Bustillo Llorente \& Fernández Macías, 2005).

Thus, the country where the biggest level of satisfaction is recorded, Mexico, with a value of 5.86 on a scale from 1 to 7 is just with $11 \%$ over the recorded average value, while in the country with the smallest level of satisfaction, South Korea, the recorded value (4.75) is just with $9 \%$ under the average.

The very small differences between the countries regarding the level of job satisfaction are very surprising taking into account the fact that the analyzed sample countries include developed countries as well as developing countries.

In countries as Switzerland, Denmark, U.S.A., Germany, France, the employees benefit of not just high salaries but a high level of social protection, very good working conditions and high life standard.

On the other hand, in developing countries being in transition or passed through periods of economic or political crisis such as Bulgaria, Russia, Mexico, South Africa, etc., the standard of life is inferior and the employees do not benefit of bonuses and with all of these they do not significantly reflect the level of the employees' satisfaction. For example, in Bulgaria, which records a level of satisfaction with only $9.21 \%$ smaller than Switzerland, and with just $0.77 \%$ than the European average in 2005 - the period from which the dates ISSP are available - according to a survey made of The Economist Intelligence Unit, the index of life quality was just 6.162 occupying the $57^{\text {th }}$ place in the world, unlike Switzerland 
which occupied the second place in the world with an index of 8.068. Moreover, although during the period 2003-2005 there was a stability period for Bulgaria, the employment rate did not decrease under $13 \%, 51 \%$ of the employees declared that their job is unsecure and the working conditions were under the ones assessed by the EU (European Foundation for the Improvement of Living and Working Conditions, 2006).

All these unfavourable conditions would justify a lower satisfaction index. It appears that they do not have a significant influence on the employees' job satisfaction.

The very high value of the average of satisfaction in the analyzed countries is also surprising, with a value of 5.27 on a seven point scale.

Taking into account this results, we can conclude that, regarding the 32 analyzed countries, the employees are relatively satisfied with the job they have. Although we ascertained the existence of a reduced variable of the satisfaction level between different countries, we analyzed how this indicator is influenced by some macroeconomic variables traditionally considered significant when we speak about satisfaction: GDP/capita (in PPP), Employment rate, Overwork, Index of the real income.

Among the chosen variables, the first influence on job satisfaction which was analyzed was the one regarding the gross domestic product per capita. We have expected that the relationship between GDP/capita, indicator of general economic welfare and satisfaction, to be a positive one. However, the relation, although a positive one, is very weak. In spite of the fact that it is an awkward result, it is in concordance with other international surveys that show that the relationship between income and satisfaction is a linear one until a point from which the income raise do not determine an increase of the "happiness index" anymore (Muñoz de Bustillo Llorente \& Fernández Macías, 2005). For example, although during the period 1952 - 1989, the gross domestic product doubled in the U.S.A., job satisfaction decreased with 0.2 points on a scale from 1 to 3 (Kenny, 1999).

Testing the relationship between the employees' job satisfaction and GDP/capita (in PPP) demonstrates the fact that there is a direct relationship between the two variables with a significance level of 0.01 . The regression descent indicates a positive relation between GDP/capita and the employees' job satisfaction, and the value of Beta coefficient of 0.23 suggests a weak relationship between the two variables.

The unstandardized regression coefficient has the value of 0.001 . This means that for each increase with 1.00 on the horizontal axis, the score from the vertical axis modifies with 0.001 . Thus, we can conclude that the level of the employees' job satisfaction is influenced by the gross domestic product per capita, but in a small measure which may be considered insignificant. The equation of the regression descent is defined by the relation: $\mathrm{y}=5.171+0.001 \mathrm{x}$, with a $\mathrm{R}^{2}=0.052$. The constant of the regression is expressed by the unstandardized coefficient $\mathrm{B}=5.171$.

Another macroeconomic indicator whose influence was analyzed is the unemployment rate. Logically, a high unemployment rate could determine the employees from a country to be more satisfied by their work by the simple reason that they have a job, no matter how this is. On the other hand, a low unemployment allows the employees to better negotiate their contracts and working conditions, which would trigger a series of factors that induce satisfaction. Furthermore, the analysis effectuated does not support any of the two hypotheses, highlighting a weak relationship between unemployment and job satisfaction. Analyzing through a simple linear regression the dependence of the job satisfaction from unemployment rate, we noticed the fact that there is an indirect relationship between the two variables as the Beta regression coefficient has a negative value, meaning that if the unemployment rate increases, job satisfaction decreases.
However, the relationship between the two variables is weak, Beta being equal with -0.301 the equation of the regression descent is defined by the relationship: $y=5.519-0.033 x$, with $\mathrm{R}^{2}=0.301$. As it can be noticed, the Person correlation coefficient is -0.301 , suggesting a weak negative relationship between the unemployment rate and job satisfaction. Otherwise, the value of $0.144>0.05$ suggests an insignificant correlation from a statistic point of view.

Regarding the overwork influence (defined as percentage of the active population that works over 50 hours per week) on the level of job satisfaction, the regression coefficient indicates a very weak Beta negative relationship having the value of 0.194. The unstandardized coefficient B has the value of 5.389, thus the equation of the regression is defined by the relationship: $y=5.389-0.002 x$, with $R^{2}=0.194$. As it can be noticed, the Person correlation coefficient is -0.194 , suggesting a weak negative relationship between overwork and job satisfaction.

Also the index of the real income influences the dependent variable job satisfaction in a small proportion, Beta regression coefficient having the value of 0.107 . The equation of the regression descent is defined by the relationship $\mathrm{y}=4.862+$ $0.004 \mathrm{x}$, with $\mathrm{R}^{2}=0.011$.

As a principle, the relationship between satisfaction and real income index should have been a positive one and the countries that recorded high income increases should have had a high level of employees' satisfaction. However, the results show a very weak positive relationship, which suggests that there are other factors, much more important for the employees than the financial ones.

\section{CONCLUSIONS}

We have made this comparative analysis of the level of job satisfaction of the employees from different countries as well as the influence of some macroeconomic indicators essential in any country economy, being aware of not just the existent differences regarding the economic development of different analyzed countries but also the multiple cultural differences that appear inevitable even at the european level. We have noticed with a certain surprise that when it comes to job satisfaction, its level does not differ too much from a country to another. Also the conclusion resulted after testing the influence of the four macroeconomic variables regarding job satisfaction is that although these external factors determine job satisfaction variation, these are relatively small and not necessarily significant.

\section{REFERENCES}

Muñoz de Bustillo Llorente, R. \& Fernández Macías, E. (2005), Job satisfaction as an indicator of the quality of work, Journal of Socio-Economics, vol. 34, issue 5

Viorel LEFTER, Ramona Ştefania PUIA, The evaluation of job satisfaction - study conducted in the organisations from Bucharest, Ovidius University Anals, Economic Sciences Series, Volume X, 2010, pp. 1096-1101

Van Saane, N., Sluiter, J.K, Verbeek, A.M. \& Frings-Dresen (2003), Reliability and validity of instruments measuring job satisfaction - a systematic review, Occupational Medicine, Vol.53, No.3, pp.191-200

Hardré, P.L. (2009) The Motivating Opportunities Model for Performance SUCCESS: Design, Development and Instructional Implications, Performance Improvement Quarterly, 22(1), pp. 5-26

European Foundation for the Improvement of Living and Working Conditions (2007), Measuring job satisfaction in surveys - Comparative analytical report, Dublin, Ireland, www.eurofound.europa.eu 